\section{A) Check for updates}

Cite this: J. Mater. Chem. B, 2021 9, 6728

Received 15th February 2021 Accepted 10th July 2021

DOI: $10.1039 / d 1$ tb00322d

rsc.li/materials-b

\title{
A review on diatom biosilicification and their adaptive ability to uptake other metals into their frustules for potential application in bone repair
}

\author{
A. Reid, (D) ${ }^{a}$ F. Buchanan, (D) ${ }^{b}$ M. Julius (D) ${ }^{c}$ and P. J. Walsh (D) $\star^{a b}$
}

\begin{abstract}
Diatoms are unicellular eukaryotic algae that have a distinctive siliceous cell wall (frustule) with unique architectures. The nanotopography of the frustule is perfectly replicated between generations, offering a source of highly intricate and identical silica microparticles. In recent years, the ability to alter their cell wall chemistry both in terms of functionalisation with organic moieties or by incorporation of the metal ions in their frustules has increased interest in their utility for catalysis technologies, and semiconductor and biomedical applications. Herein we review the fundamental biological mechanisms in which diatoms produce their frustule and their ability to substitute different metal ions in their frustule fabrication process. The review focuses on the potential of diatom frustules as a naturally derived biomaterial in bone tissue engineering applications and how their cell walls, comprising biogenic silica, could either partially or fully incorporate other bone therapeutic metal ions, e.g., titanium or calcium, into their frustule. The use of diatom frustules in bone repair also potentially offers a 'greener', more environmentally friendly, biomaterial as they can naturally synthesise oxides of silicon and other metals into their frustules under ambient conditions at a relatively neutral $\mathrm{pH}$. This process would negate the use of harsh organic chemicals and high-temperature processing conditions, often used in the fabrication of silica based biomaterials, e.g., bioactive glass.
\end{abstract}

\section{Introduction}

Bone defects require the use of biomaterials when the bone cannot repair itself. Most bioceramics for bone repair tend to be either hydroxyapatite or calcium phosphate-based materials, although in recent years silica-based biomaterials such as bioglass have shown significant promise. Bioglass ${ }^{\circledR}$ or calcium sodium phosphosilicate is a bioactive implantable glass that is specifically composed of 45 wt $\% \mathrm{SiO}_{2}, 24.5 \mathrm{wt} \% \mathrm{CaO}, 24.5 \mathrm{wt} \%$ $\mathrm{Na}_{2} \mathrm{O}$, and 6.0 wt $\% \mathrm{P}_{2} \mathrm{O}_{5} \cdot{ }^{1,2}$ It was the first artificial material of its kind to chemically bond with bone, and since its discovery, has led to the development of numerous other silicon-based bioactive glasses. ${ }^{3}$ Studies have shown that this material has the ability to enhance bone formation. ${ }^{4}$ When implanted into rabbit femurs, the bioglass $45 \mathrm{~S} 5$ induced bone proliferation at a much quicker rate than synthetic hydroxyapatite (HA). ${ }^{5}$

There is evidence in the literature that diatom cell walls (frustules) can provide a natural source of silica that is suitable for implantable silica biomaterial. ${ }^{6,7}$ Diatoms are a unicellular microalga that have unique silica cell walls. In addition to

\footnotetext{
${ }^{a}$ School of Chemistry \& Chemical Engineering, Queen's University, Belfast, UK. E-mail: areid41@qub.ac.uk, Pamela.walsh@qub.ac.uk

${ }^{b}$ School of Mechanical \& Aerospace Engineering, Queen's University, Belfast, UK

${ }^{c}$ Biological Sciences, St. Cloud State University, St. Cloud, MN, USA
}

producing these silica frustules, they also have the ability to incorporate other metals. This makes them more attractive as a biomaterial candidate, as there is potential to substitute therapeutic metals such as strontium, zinc. It is interesting to note that they naturally have a complex 3D micro/nanotopography with pores and ridges. Nanotopography is advantageous in bone repair as surface roughness as it is thought to enhance osseointegration as it promotes absorption of proteins and adhesion of osteoblast (bone forming cells). ${ }^{8}$ Further benefits of surface topography and its ability to enhance bone formation in bone repair are reviewed by Rabel et al. ${ }^{9}$ In addition to their physical attributes diatom frustules have been shown to be non-cytotoxic to both J774.2 macrophage cells and bone marrow stroma cells, while supporting cell proliferation and growth. ${ }^{7}$ Other studies have shown the potential benefits that diatoms have for promoting bone cell growth, ${ }^{10}$ such as the work carried out by Cicco et al. which not only illustrated the ability of the diatoms frustules to allow for bone cell adhesion and enhance cell proliferation, but also gave an insight to the highly tuneable nature of this material by illustrating its ability to be used for antibiotic drug control and by covalently functionalising the frustule with TEMPO, a radical oxygen scavenger, with the potentially ability to prevent the adverse effects of inflammation. ${ }^{11}$ Although diatom frustules have shown significant promise as a drug delivery system, this is beyond the 
scope of this review. Before, reviewing metal substitution in diatom frustules it is important to firstly understand frustule formation and biosilicification.

\subsection{Diatom frustule}

The diatom frustule are comprised of biogenic or opaline silica, chemically known as hydrated silica $\left(\mathrm{SiO}_{2} \cdot n \mathrm{H}_{2} \mathrm{O}\right) \cdot{ }^{12}$ As previously mentioned, the frustule is comprised of two that are held together by girdle bands that are also patterned silica structures. These girdles extend around the entire circumference of the diatom and collectively form the complete cell wall. A typical example is shown in Fig. 1 for Cyclotella meneghiniana a freshwater centric diatom.

The cell walls contain many small pores and openings to allow membrane contact and exchange of small molecules with the external environment. These intricate and nanoporous cell walls replicate near perfectly between generations (see Section 1.3). Each species has their own unique frustules. Examples of different types of frustules are shown in Fig. 2.

\subsection{Biosilification}

Diatoms form their intricate and ornate siliceous frustules via a process called biosilification. Research continues to better understand this often-mysterious process, and some steps of the process

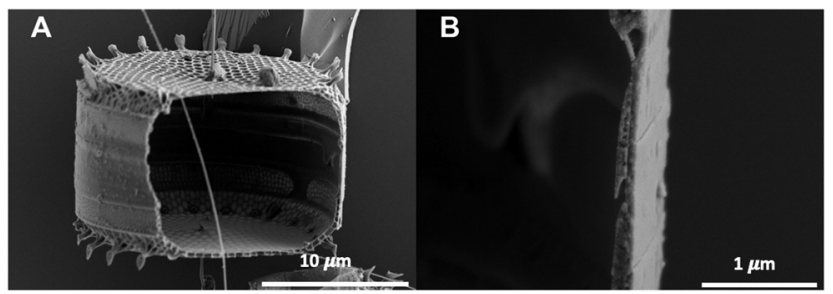

Fig. 1 Scanning Electron Microscopy image of (A) the whole frustule of Cyclotella meneghiniana with cross-section and (B) cross-section of frustules cell wall. Note the ornate structure, nanopatterning, porosity and spikes on the silica wall. With permission of co-author Prof. Matthew Julius \& Dr Shegeki Mayama Tokyo Gakugei University.

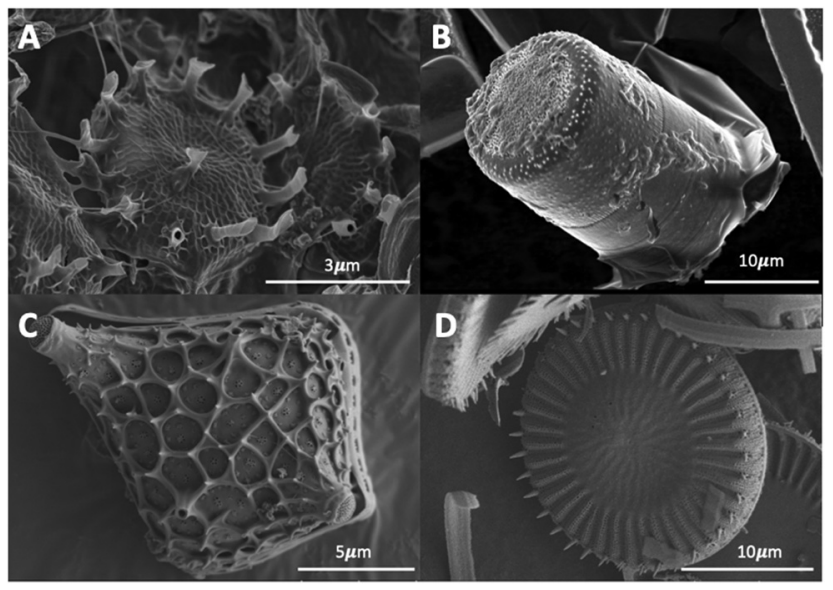

Fig. 2 Diatoms frustules with organics removed (A) Skeletonema pseudocostatum (B) Melosira varians (C) Triceratium dubium (D) Cyclotella meneghiniana. Samples imaged by co-author P. Walsh at Northwestern Nuance Centre, Evanston, USA. remain elusive, although multiple competing theories exist. The diatoms need a silica source for frustule construction from their external environment. Soluble silicon is found in moist or aquatic environments in the form of orthosilicic acid $\left(\mathrm{Si}(\mathrm{OH})_{4}\right) \cdot{ }^{13}$ It comprises $97 \%$ of total dissolved silicon. Diatoms predominately utilise this silicic acid, but it is unknown if other silicon forms are utilised by diatoms.

Diatoms are so efficient at up-taking silicon from their surrounding environment that they can virtually deplete the silicon levels to such an extent that it becomes undetectable using standard water analysis techniques. ${ }^{14}$ As a result, diatom populations are frequently silica limited ${ }^{15}$ and will "bloom" if their surroundings are enriched by run-off from a silica-rich source (either from a factory waste run-off or from natural sediments). If silica is depleted, their population will begin to plateau before declining, allowing other algae that do not rely on silicate to become dominant.

The uptake of silicates from the diatoms' surrounding environment and incorporation into cell was first reported by Lewin. ${ }^{16,17}$ Del Amo and Brzezinski (1999) then reported that the most common silicon species taken into diatoms is unionised silicic acid $\left(\mathrm{Si}(\mathrm{OH})_{4}\right)$, which is predominant at $\mathrm{pH} 8.0$ of seawater. ${ }^{18}$ The material must first enter through pores in the frustules before then crossing the plasmalemma, the primary membrane which is found immediately within the cell wall. The complete mechanism for silica uptake is not entirely understood, with the current research suggesting that there may be multiple pathways. Oceanic seawater concentrations of silicic acid typically range from $<1$ to $70 \mu \mathrm{M}$, however the concentration inside the diatoms cell body can range from 19 to $340 \mathrm{mM} .{ }^{19}$ This extremely large gradient suggests the process is not a function of simple passive diffusion across the cell membrane, ${ }^{20}$ but rather a function of active transport. There are several theories, including protein mediated uptake by specialised silicon transfer proteins (SITs). ${ }^{21-23}$ Chemostat studies suggested three different uptake models ${ }^{24,25}$ with the dominant mode being environment dependant. The three proposed modes are: (i) surge uptake, (ii) externally controlled uptake, and (iii) internally controlled uptake.

The silicon transport system was first molecularly characterised with the cloning of the silicic acid transporters from the diatom Cylindrotheca fusiformis. ${ }^{22}$ Bhattacharyya and Volcani then showed that transport in marine diatoms appears to be sodium-coupled, ${ }^{26}$ therefore the transporter acts as a silicic acid \& sodium symporter, and other indirect evidence suggests electrogenic transport and the ratio of $\mathrm{Si}(\mathrm{OH})_{4}: \mathrm{Na}^{+}$being $1: 1{ }^{19}$ The uptake of silicic acid is not continuous, and it peaks around the $\mathrm{G} 2$ and $\mathrm{M}$ phases, when DNA replication has occurred, and cell division imminent. Silica uptake peaks particularly during the formation of new valves and girdle elements, and then declines throughout the rest of the cell's life. ${ }^{27}$ Sullivan (1997) demonstrated this during the course of the cell cycle in Navicula pelliculosa. In most diatom species, silicic acid transport and cell wall silica deposition are temporally coupled. $^{28}$

Once the silicates have been taken into the cell, they must be transported within the cell in order to be utilised. Little information 
is known concerning silicic acid transport within the cell beyond that reviewed by Martin-Jézéquel $e t a l^{19}$ and more recent work by Knight et $a .^{29}$ Drum and Pankratz showed that silica formation is an intracellular process that takes place within membranelimited compartments, which they termed silica deposition vesicles (SDVs). ${ }^{30}$ These SDVs have been characterised as acidic compartments that are fused with Golgi-derived vesicles. ${ }^{31}$ Within the SDVs silicic acid is stored at a concentration beyond saturation. The amorphous silica within the SDVs is used to form the diatom frustule. Once complete the diatom frustule is exocytosed into place outside the cell membrane. The biosilicification reaction in the SDV can occur in an uncontrolled manner (autopolymerisation) and could occur within the cell cytoplasm; this must be and is avoided. This suggests process is more complicated than a simple, uncontrolled polymerisation as the frustules contain intricate nanostructured patterns that replicate near perfectly between generations, implying strict control.

Drum and Pankratz showed that silica formation is an intracellular process that takes place within membrane-limited compartments, which they termed silica deposition vesicles (SDVs). ${ }^{30}$ These SDVs have been characterised as acidic compartments that are fused with Golgi-derived vesicles. ${ }^{31}$ Within the SDVs silicic acid is stored at a concentration beyond saturation. The amorphous silica within the SDVs is used to from the diatom frustule. However, where the conversion of the silicic acid (monomer) into a silica polymer occurs is still unknown and subject to much debate. Martin-Jézéquel et al. suggests that the site of polymerisation occurs within the SDV. ${ }^{19}$ This theory is supported in a review by Baines et $a l .^{32}$ who theorises that high intracellular silicic acid concentration within the SDV means polymerisation is unlikely to occur outside it. This literature suggests that silicon is taken quickly up within the SDV and used equally quickly, however, during non-divisional cycles large concentrations of silicon is not present. However, other literature suggests that different pathways may play a role in silica polycondensation. Recently, the silicon storage pools in Thalassiosira pseudonana, have been reported to be homogeneously distributed throughout the entire cell interior, ${ }^{33}$ as opposed to only within the SDV. This is backed-up by solid-state NMR data on diatom cells that has shown stored silica precursors are pre-condensed silica species as opposed to monosilicic acid. ${ }^{34}$ Other work has further dispelled this theory by suggesting nanoparticles of silica form outside the SDV. Using fluorescent dyes to strain growing siliceous frustules, Annenkov et al., reported the presences nanoparticles in the cytoplasm of diatoms, which they suggest are then transported to the SDV where they fuse together. ${ }^{35,36}$ Grachev et al. work on the same pennate shaped diatom species, Synedra acus, supports Annenkov findings. ${ }^{37}$ Martin-Jézéquel et al. acknowledges polymerisation in the cytoplasm but suggests it is the result of an uncontrolled autopolymerisation that can occur when not enough silicon is transported to the SDV.$^{19}$ Vrieling et al. suggests that silicic uptake in the vicinity of the SDV is more likely also to prevent autopolymerisation, otherwise stabilisation of the silicic acid and/or precursors would be required..$^{38}$ The most recent work by Annenkov et al..$^{39}$ completely contradicts all theories to date by suggesting that silica polymer formation takes place outside the cell and is ingested by the diatom in a process known as pinocytosis.

The polymerisation process is complicated even further by the strict control that is required to produce frustules contain intricate nanostructured patterns that replicate near perfectly between generations. The first attempt to explain this control within frustule formation came from Hecky et al. who proposed a hypothetical arrangement of organic layers present in the preexisting frustule, where a protein template (rich in glycine, serine and threonine) interacts with the mineral phase and an outer layer of polysaccharides acts as a buffer system. ${ }^{40}$ More recently, these protein templates have been found in Cylindrotheca fusiformis cell walls, ${ }^{41}$ and are now referred to as silaffins. Silaffins are sets of polycationic peptides that have been shown to extracellularly catalyse the polymerisation of silica spheres (which are similar to diatom biosilica frustules) after having been first isolated from Cylindrotheca fusiformis cells by Kröger et $a l .{ }^{42}$ Further information regarding the structure and more detailed roles of silaffins within the nanofabrication processing of diatom biosilica has been well documented by Kröger ${ }^{43}$ and Wetherbee. ${ }^{44}$ Since the discovery of silaffins by Kröger et al. other silica attached molecules have been identified, suggesting that silaffins alone are unlikely to be the only major silica biosynthesis involved molecules. In 2008, Wenzl et al., discovered a new class of peptides in Thalassiosira pseudonana that are involved in biosilica production, which they coined silacidins. ${ }^{45}$ They hypothesised that the silacidins act as the polyanion in the silica formation that is directed by the silaffins. Kröger et al. also identified the involvement of long-chain polyamines in silica formation, which was later supported by Sumper et al., who suggested that pattern formation was dependent on these longchained polyamines in conjunction with the silaffins. ${ }^{46,47}$ These long-chained polyamines have also been identified in sediment biosilica. ${ }^{48}$ More recent work, by Jantschke et al. used solid state NMR to identify five amino acids in the native proteins associated with biosilica formation, namely; serine, alanine, glycine, aspartic acid, and glutamic acid. ${ }^{49}$ Kolbe $e t$ al. also used similar techniques to gain a better understanding of the organic matrix associated with the silica and found high concentrations of glucosamine, an amino sugar. ${ }^{50}$ Although significant progress has been made in this field, these findings would suggest much work is still needed to fully understand the other major molecules involved in diatom biosilica formation.

The process by which the silicified wall components of diatoms are precisely fabricated is controlled by two interactive mechanisms, called macromorphogenesis and micromorphogenesis. ${ }^{51}$ Macromorphogenic processes are those on a larger scale, controlling the large-scale patterning and silicification, and is determined by both the environment and constraints of the SDV. Cytoplasmic components (such as actin filaments and microtubules) ${ }^{52,53}$ imprint on the SDV to shape the forming wall. Macromorphogenesis processes are responsible for the distinct morphological features, such as pores, slits, and chambers. ${ }^{51}$ However, macromorphogenesis alone is insufficient to fully explain the nanostructure of diatom walls. ${ }^{54}$ The nanofabrication process cannot be explained as simply a result of spontaneous autocondensation 
and accumulation of silica within the SDV. This leads to the second of the two processes is called micromorphogenesis ${ }^{44,55}$ which occur in the lumen of the SDV and on the inner surface of the silicalemma. It depends on the activities of organic matrices at the inorganic interface. Further information on these processes can be found elsewhere. ${ }^{56}$

\section{Functionalising frustules via metal substitution}

Diatoms are typically autotrophic primary producers. They require trace metals and vitamins to perform their metabolic functions, which must be obtained from the environment. These trace metals are mostly required enzyme production, for example magnesium is a central metal cofactor in chlorophyll. ${ }^{57,58}$ Additionally iron, like nitrogen and phosphorus, is a crucial element, that is used in protein production for the respiratory electron transport system. ${ }^{59}$ Ecological and palaeontological studies have showed that diatoms were capable of taking up heavy metals (such as cadmium and lead) and other contaminants from their surroundings. ${ }^{60,61}$

It was during the 1970 s that it was first observed that materials other than silica could be incorporated into the siliceous cell walls of diatoms. Riley \& Roth carried out a study of fifteen phytoplankton species to determine the abundance of eighteen trace elements. ${ }^{62}$ Whilst this was not the first study of its kind, it did confirm prior observations reported by Knauss and Porter of the correlation between the trace element contents of large marine algae and their growth medium, ${ }^{63}$ as well as the presence of iron, manganese and zinc in Phaeodactylum tricornutum. ${ }^{64}$ The study also suggests that the distribution of trace elements is not correlated with taxonomy. It was observed that differences in the concentration of several elements, specifically copper, manganese and tin, were often greater between species in the same genus than those of different classes.

Martin \& Knaeur conducted similar studies and investigated the presence of the trace metals in both the organic (cell) fraction as well as the inorganic silica frustule. ${ }^{65}$ Their results showed that aluminium, iron, and titanium were nearly always present within the frustule, even if absent from the organic fraction. The study also reported maximum observed uptakes of $\mathrm{Al}: 1.600 \mathrm{wt} \%$, Fe: $0.282 \mathrm{wt} \%$ and $\mathrm{Ti}: 0.125 \mathrm{wt} \%$, with the rest of the values being much lower $\sim 0.01 \mathrm{wt} \%$. Aluminium was found to be consistently present at the highest weight percentage, and finally a correlation appeared to exist between iron and titanium within the frustule. Martin \& Knaeur theorised that it was highly likely their samples contained populations that were no longer actively growing (due to slow turnover rates of the population), which indicated that the cells had sufficient time for maximum uptake of several elements. ${ }^{65}$

Once it was established that metals could be incorporated into the diatom frustule, a whole new plethora of possibilities has been unlocked. There is now the ability to tailor the chemistry of diatom frustules, and the potential to form functionalised biomaterials, each tailored to their specific applications.

\subsection{Metal substitution by in vivo feeding}

The "in vivo feeding" method of functionalising frustules makes use of the natural biological processes carried out by diatoms in order to incorporate materials other than silica into the cell. As there is still no conclusive study detailing the exact mechanism(s) for silica uptake, we are unaware of how other materials (such as metals) are brought into the cells. It is likely that this occurs through passive diffusion through the frustule pores, as even "their nutrient uptake systems exhibit only mediocre nutrient affinities". ${ }^{66}$ Regardless of how the material is brought into the cell, it is well understood that it can find its way into the cells organic phase (protoplasm or occasionally incorporated into the various membranes) or into the inorganic frustule. To date most research has been carried out with the desired goal of finding a process to drive the uptake of the metal dopants, both in terms of uptake of a higher concentration of metals and also for targeted deposition of the dopant into the silica network of the frustule.

This process appears simple, a soluble species of the desired dopant (typically a soluble salt of a metal) is added to the growth medium, and the diatom cell, can naturally uptake the metals using the biological mechanisms of silica uptake and biosilification. It should be noted however, that in reality, the process is a lot more complex. Firstly, as previously discussed, our understanding of biosilification is still developing, as we have not completed our understanding of the process from start to finish. This makes understanding the uptake of the dopants more problematic.

The in vivo feeding method requires the dopant, nearly always a metal, to be present in the diatoms' growth media in order for the diatom to up take the material into their cell. The easiest method to do this is to simply add the metal in the form of a soluble salt. This requires careful planning to determine the optimal salt, with two key concerns that must be considered; the solubility and toxicity. The salt must first dissolve in the growth media, in order for the diatom to be able to take up the metal ions. Salts have varying degrees of solubility, which is also influenced by the media itself (marine water will reduce solubilities due to pre-existing salinity). Finally, the salt must stay in solution after stirring or mechanical agitation and no precipitate back out after mixing has stopped. Toxicity can come about from simply the diatoms' maximum tolerable concentration of metal being exceeded or from the competitive inhibition of other metals by the dopant. Finally, some salts, particularly metal hydroxides may be soluble but will dramatically alter the growth media's $\mathrm{pH}$, which may result in cell death. Ideally, a very soluble non-toxic salt of the desired dopant will be found and once added, will have a high affinity and will be rapidly taken up by the cell. Most of the time this will not be feasible and so it becomes a delicate balancing act between biocompatibility, solubility, toxicity and utilisation.

2.2 Successful metal substitution into diatoms frustules that has potential applications in bone repair

2.2.1 Germanium. The first studies exposing diatoms to germanium came from Lewin et al. who tried to inhibit the 
Table 1 Summary of a selection of key papers that utilise metal incorporation to functionalise diatom frustules for additional applications

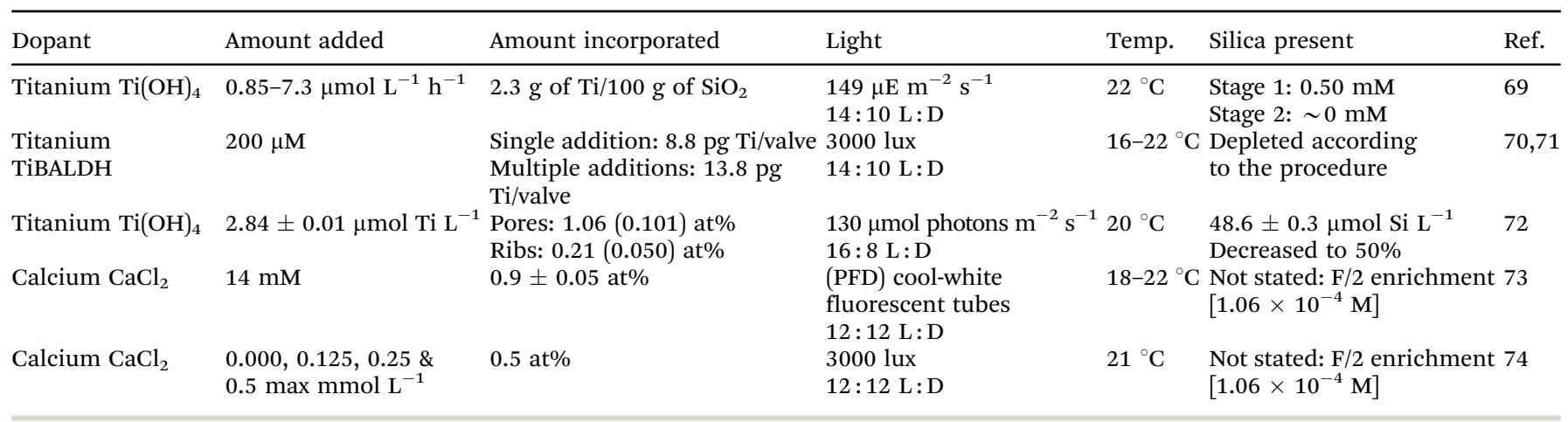

growth of diatoms infecting other algal cultures. ${ }^{67}$ The Germanium was added in the form of germanium dioxide, and the theory was that it is so chemically similar that it would likely be a competitive inhibitor, taken up in lieu of the silicic acid and therefore disrupt the frustule formation of the diatoms. The first reported case of deliberately incorporating foreign elements into diatom frustules was conducted by Azam et al., who was able to show that germanium, in the form of radioisotopically labelled Germanic acid, ${ }^{68} \mathrm{Ge}(\mathrm{OH})_{4}$, was able to be taken up by diatoms, and incorporated into their frustules, which disrupted their formation. ${ }^{68}$ After this study many more have been carried out showing similar incorporations of other foreign elements into the silica network of the frustule. A summary of some of these studies are shown in Table 1.

2.2.2 Titanium. Titanium substitution has had the most interest. Titanium has been substituted for semiconductor $\mathrm{TiO}_{2}$ nanostructures, ${ }^{69}$ photocatalysts ${ }^{75}$ and to simply better understand the biology of diatoms. ${ }^{72}$ These studies have some major overlaps, namely the process of metabolically inserting titanium by growing the cultures in a depleted silica medium, either by purposefully limiting the species in the growth media or growing cultures until the silica has been consumed by the cells. Additionally, these publications clearly illustrate the requirement of finding concentrations that are high enough to ensure that insertion of titanium occurs, while being low enough that the addition of the metal had no detrimental effects on cell growth and preserved the frustule morphology. Finally, the concentration must also be low enough to circumvent precipitation in the growth medium.

2.2.3 Calcium. Leone et al. reported a simple method to produce calcium-doped biosilica supports for bone tissue regeneration by the in vivo feeding of algae with $\mathrm{CaCl}_{2}$ salts. $^{73}$ The method is extremely simple, cost effective and environmentally. It simply adds the desired metal to the growth media in the form of a soluble salt, and the diatom takes up the metal ion via normal metabolic pathways (not that well understood) and incorporated itself into both the organic cell and inorganic frustule. Fourier-transform infrared spectroscopy (FTIR) and Energy-dispersive X-ray spectroscopy (EDX) analyses confirmed the incorporation of calcium into the mesoporous biosilica. The FT-IR spectra of purified diatom frustules grown in a medium with and without $\mathrm{CaCl}_{2}$ showed the typical signals related to the symmetric stretching of the $\mathrm{Si}-\mathrm{O}-\mathrm{Si}$ bound $\left(884 \mathrm{~cm}^{-1}\right)$, the asymmetric stretching of $\mathrm{Si}-\mathrm{O}-\mathrm{Si}\left(1175 \mathrm{~cm}^{-1}\right)$, the $\mathrm{Si}-\mathrm{O}-\mathrm{H}$ stretching (584-450 $\left.\mathrm{cm}^{-1}\right)$ and the $\mathrm{Si}-\mathrm{O}-\mathrm{C}$ stretching (1066$1009 \mathrm{~cm}^{-1}$ ). This confirms that the additional calcium did not cause any covalent modification of the biosilica. The EDX showed that the frustules of the diatoms in the control group contained $0.0 \pm 0 \%$ $\mathrm{Ca}^{2+}$ whereas the doped frustules contained $0.9 \pm 0.05 \% \mathrm{Ca}^{2+} . \mathrm{Li}$ et al. detailed similar success in incorporating $\mathrm{Ca}^{2+}$ into the frustule of another species of diatom using a similar "in vivo feeding" process. ${ }^{74}$ After the feeding EDSX of cleaned frustules showed the presence of a previously absent Ca peak, while the SEM did not appear to show any morphological changes.

Calcium is of particular interest as unlike germanium and titanium it does not form a binary oxide $\left(\mathrm{MO}_{2}\right)$. The natural form of silicon utilised for the frustule is silica $\left(\mathrm{SiO}_{2}\right)$, and so other binary oxides may be incorporated into the frustule using much the same mechanisms as biosilification, and as calcium does not form a binary oxide it must be incorporated via a different pathway. Due to the chemical similarities between group 2 elements, it is very likely that the other metals in this group could also be incorporated into the frustule, leading to more potential applications. Other nongroup 2 metals have been successfully incorporated into diatom frustules, that include Nickel, Tin and Aluminium, which have been reviewed by other authors. ${ }^{76}$ We propose that group 2 metals within the silica network of the frustule, like the calcium doping studies carried out by Leone $e t$ al. and Li et al. is of particular interested in biomedical engineering, particular bone tissue repair. Likewise, strontium and magnesium are of interest as they share similar chemistries and properties to magnesium, therefore whilst not guaranteed, it is highly likely that if diatoms can incorporate calcium then similar results could be expected with magnesium and strontium. Both these metals have shown promise as therapeutic for bone regeneration as detailed below. Their incorporation into the frustule could offer a novel treatment for bone disorders; both metals have been shown to increase bone formation and regeneration.

\section{Bone regeneration}

One of the most recent frontiers in the use of diatoms comes from the medical field. Diatoms have recently garnered a lot 
Table 2 Studies detailing the beneficial effects of diatom frustules on bone health and cell proliferation

\begin{tabular}{lll}
\hline Dopant & Method of functionalisation & Application \\
\hline None & - & Source of silicon for bone tissue engineering \\
None & - & Treat \& prevent osteoporotic disorders \\
TEMPO & Linking (covalent) & Support material for cell growth \& proliferation \\
Amine (APTMS) and thiol (MPDMS) & Linking (covalent) & Exploration of cytotoxicity \& support of bone tissue engineering \\
Organosilanes & Linking (covalently) & Support material for cell growth \& proliferation
\end{tabular}

attention for their potential therapeutic uses. This includes drug delivery and biosensing but also in bone regenerative medicine and (cellular) growth supports. Multiple studies already exist (see Table 2) detailing the benefits of diatom biosilica for such purposes, however to this point the frustules are largely unfunctionalised and thus the field is still in a juvenile phase with much more research needed to unlock its true potential. It is the combination of the rough nanotextured surface and the silica compositions of the diatom frustules that make them of interest for bone health and tissue regeneration applications.

\subsection{Surface roughness}

Frustules are intricately patterned, typically highly porous, often with a variety of pores, ribs, spines, ridges and elevations. These complex nano-topographies are required for functional use by the diatom. They are used for identification purposes between genera and species by diatom physiologist. In biomedical applications their rough surface is beneficial for providing a surface support for cell growth and proliferation. Several studies observing different implantable materials all reported that rougher surfaces resulted in enhanced cell attachment and proliferation as opposed to smooth or polished counterparts. It has been reported that rougher surfaces are better for enhancing cell attachment and proliferation ${ }^{77}$ than polished counterparts. ${ }^{78}$ One such study showed the effect of different etchings to create roughness on a titanium surface enhanced growth and proliferation of MG-63 osteoblast cells. The study concluded that rougher textured surfaces, had a lower cytotoxicity level and better biocompatibility than smooth controls. This was attributed to the fact that the rough surfaces "encourage the entrapment of fibrin protein, adhesion of osteogenic cells and mechanical stability of implants in host bone ${ }^{, 79}$ which is also reported elsewhere. ${ }^{80-82}$ In conclusion, it would appear that there is a positive correlation between surface roughness and cellular attachment and cell proliferation. Therefore, diatom frustules are likely to be of significant benefit in bone repair for this precise reason.

\subsection{Silicon}

In addition to the rough surface of the frustule, it has a silica chemistry, which in itself is hugely beneficial for optimal bone growth. Silica ions are known to be involved in the bone mineralisation process, most likely by controlling different stages of calcification. However, the role of silica in bone regeneration is not fully understood at present. It has been shown that silica induces the precipitation of calcium phosphate in early stages of biocalcification. ${ }^{83}$ Early dietary studies showed that the silica concentration was 25 times greater in the osteoid layer than in the adjacent periosteum, in tibia samples from young mice and rats. Carlisle noted that enhanced calcification resulting in gradually decreasing Si content. ${ }^{84}$ Silicon has also been shown to be essential for connective tissue, stimulating osteoblast proliferation ${ }^{85}$ and inhibiting osteoclast formation and thus bone resorption. ${ }^{86}$ Dietary supplements have also been shown to increase bone quality (strength and density) in growing animals. ${ }^{87}$ However, the biosilica need to be bioresorbable in vivo thereby releasing silicon ions.

Implantable silica, such as diatom biosilica has been shown to release silicon ions making it a suitable candidate for bone repair. ${ }^{88}$ Diatom frustules have been shown to have biologically beneficial attributes, such as providing a rough surface for cell growth and proliferation. ${ }^{7}$ However, to date metal substituted frustules for bone health applications has not been explored. Some studies have functionalised diatoms with organic linkers to offer better versatility in bone graft applications, for example, one study by Cicco et al., successfully covalently bonded TEMPO-APTES an organic linker on diatom frustules and found it supported fibroblasts and osteoblast-like cells growth. ${ }^{11}$ Walsh et al., also successfully functionalised diatom frustules with an amine and thiol linker and found the amine linker only to be non-cytotoxic to J774.2 macrophage cells, and supports cell proliferation and growth of human bone marrow stromal cells. ${ }^{7}$

Silica has been considered as an implantable material for several decades due to its relative chemical inertness, its ability to fuse to bone and upon resorption silicon ions are released (which are beneficial). Bioglass $45 \mathrm{~S} 5$ is a calcium sodium phosphosilicate that is a commercially available silica-based filler for bone applications. It is more commonly referred to by the commercial names Bioglass ${ }^{\mathbb{R}}$ and NovaMin ${ }^{\mathbb{R}}{ }^{2}$ However, Bioglass has a number of shortcomings, the most significant being its difficulty to fabricate into composite based biomaterials for load bearing application. ${ }^{90}$ Two major drawbacks of synthetic silica microparticles is their lack of porosity and the highly toxic chemical process (e.g. hydrofluoric acid) required to fabricate them. Another issue with both natural and synthetic silica is its very slow resorption rate, which is important in bone. However, the nanoporous in diatoms is likely to improve its bioresopton compared to synthetic silica in situ in bone. Additionally, diatom biosilica could offer a more sustainable source of silicon-based materials, ${ }^{91,92}$ as its synthesis does not require the use of harsh chemicals, conditions, or any energy-intensive processes like those routinely required in the synthesis of synthetic silica biomaterials. ${ }^{93-95}$ Synthetic silica used for biomaterials is usually in the form of $\mathrm{SiO}_{2}$ nanoparticles derived from the 
sol-gel reaction, ${ }^{96}$ in which a silicon alkoxide undergoes hydrolysis and polycondensation reactions to form a colloid. ${ }^{97}$ The nanoparticles can then undergo further processes such as calcination or etching depending on their desired properties and end-goal application. Many of the processes involve ammonia, $\mathrm{HCl}$, and extensive heating. ${ }^{98}$ The silica production in diatoms is carried out naturally, with the energy coming from photosynthesis. ${ }^{14}$

\subsection{Metal ions}

In addition to the benefits offered by the biogenic silica, the diatoms, as previously mentioned, will also have ions integrated into their frustules. This is typically achieved via an "in vivo" approach, which has been successful in other studies. ${ }^{73,74}$ A range of metals have been incorporated, including calcium, germanium and titanium. This is exciting as the "in vivo" approach simply relies on the diatom's own biological functions (of reproduction and cell wall production) to incorporate the material into itself. This means, that for the most part, the process is rather simply and does not require energy input (unless grown indoors using lights). We feel that this entry to functionalised frustules could be harnessed to develop a new generation of marine biomaterials with added functionality for bone regenerative medicine. Magnesium and strontium ions both make for fantastic candidates for dopants for this role, as they are group 2 metals like $\mathrm{Ca}$, which has already been shown to be taken up successfully. ${ }^{73,74}$ Fig. 3 shows an example of metal bonding to the silanol groups in diatoms. Additionally, these metals are already well known to play beneficial roles in bone formation and health and are often deficient through dietary means alone.

\subsection{Magnesium}

Magnesium provides cellular, chemical, and hormonal control in bone, $\mathrm{Mg}^{2+}$ is also known to stimulates osteoblast proliferation. ${ }^{99}$ He et al., reported magnesium ions increased cell proliferation, alkaline phosphatase active and osteocalcin levels in human osteoblast cells. ${ }^{99}$ It has also been shown that the magnesium significantly promoted the gap junction intercellular communication (GJIC) of osteoblasts, which is thought to lead to their proliferation. ${ }^{100}$ Magnesium not only increases the activity of osteoblasts, but also reduces the activity of osteoclasts.

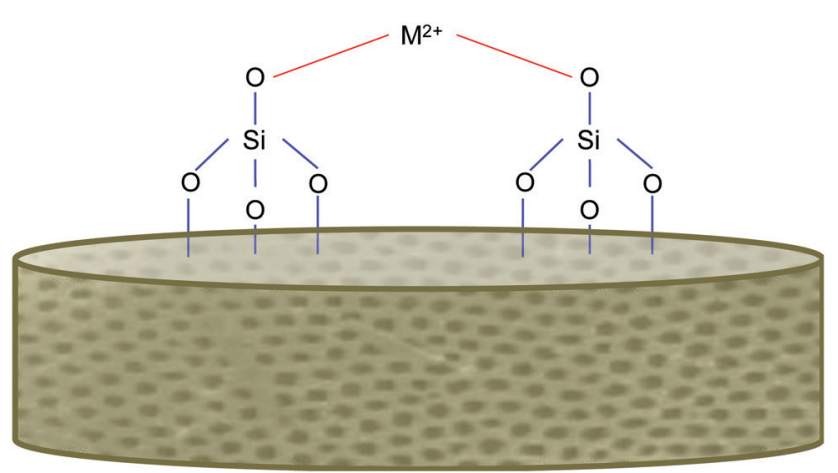

Fig. 3 Simplified schematic of metal bonding to silanol groups on the diatom frustule's surface, inspired from other sources. ${ }^{74}$
Magnesium has been shown to inhibit the release of proinflammatory cytokine molecules, including such molecules as: interleukin- $1 \beta$, tumour necrosis factor- $\alpha$, and Substance $\mathrm{P},{ }^{101}$ which are all known to stimulate osteoclast activity. ${ }^{102}$ In terms of bone structure, $\mathrm{Mg}^{2+}$ ions have shown the ability to bind to the surface of the hydroxyapatite crystals and increases the solubility of the minerals in the crystal, which results in two outcomes effecting crystal formation and size. ${ }^{103}$ The increase in solubility firstly prevents the crystal lattice from going too large, and secondly, induces imperfections into the lattice. At first this may seem detrimental but in actual fact it is beneficial as too large and perfectly formed crystals will result in more brittle bones that are more susceptible to fractures. ${ }^{104}$

\subsection{Strontium}

The mechanism for which strontium interacts with bone is derived from its similarities to calcium, that allows strontium to interact within some osteoblast-mediated processes that are typically dominated by calcium in bone metabolism. Specifically, it is believed that strontium activates the calcium sensing receptor in osteoblasts. ${ }^{105,106}$ This has a twofold effect, firstly it leads to the activation of MAPK signalling, which in turn leads to cell replication. Additionally it also stimulates the osteoblasts to produce osteoprotegerin (OPG), ${ }^{107,108}$ also known as osteoclastogenesis inhibitory factor, which is a soluble receptor. Increased levels of OPG suppresses the expression of the Receptor Activator of Nuclear factor Kappa beta Ligand (RANKL), thus inhibiting RANKL-induced osteoclastogenesis. ${ }^{109}$ Overall Strontium promotes osteoblast proliferation, differentiation, and viability while also inducing the apoptosis of osteoclasts that result to the decrease of bone resorption.

\subsection{Benefits of in vivo metal substituted diatom frustules in bone repair}

Nature has evolved an affinity to synthesise novel inorganic silica structures under ambient conditions. Protein molecules act as a catalyst to fabricate complex porous structures at (or close to) neutral $\mathrm{pH}$. This negates the use of toxic organic chemicals or high temperatures in their fabrication, making it an inherently 'greener' process to fabricate bone filler materials. This process can potentially be translated to the substitution of other group 2 metals, including magnesium and strontium which are both desirable in bone filler materials. Metal substitution of frustules therefore opens up the scope to create more tailored solutions for bone repair. Given that there is an estimated 200000 different diatom species with approximately 184 new species being identified each year, which has remained constant since $1900,{ }^{110}$ there is huge potential resource of uniquely structured materials. This offers vast potential in both bone tissue engineering and other biotechnology applications.

\section{Conclusion}

As our understanding of diatoms continues to increase, we are finding new and innovative ways to utilise their properties. 
The perfectly replicated highly textured and porous siliceous cell wall is already a valuable biomaterial, however, with the developing abilities to functionalise the frustule with various metals, the list of potential applications is vast. Biomedical applications are a vast subcategory, and bone regenerative technologies are a particularly viable area of interest. The silica of the frustule is shown to be beneficial even in its natural state, however with the incorporation of therapeutic metals, such as magnesium and strontium, this could be a huge leap in bone medicine, and overcome previous hurdles. Finally, diatoms are easily cultivated and processing their frustules does not require hazardous chemicals or large amounts of energy, resulting in a more sustainable material overall.

\section{Conflicts of interest}

There are no conflicts to declare.

\section{Acknowledgements}

Thank you to Jean-Baptiste Berard (IFREMER, France) and Jean Paul Cadoret (formerly at IFREMER, France) for biomass sample of Skeletonema pseudocostatum for imaging and Eric Miller for help with SEM at Northwestern Nuance Centre, Evanston, USA. The authors would like to thank Stephen Hull for editorial proofreading of this manuscript. Finally, we would like to thank the Engineering and Physical Sciences Research Council (Grant No. EP/R513118/1) for funding our research.

\section{References}

1 M. N. Rahaman, D. E. Day, B. Sonny Bal, Q. Fu, S. B. Jung, L. F. Bonewald and A. P. Tomsia, Acta Biomater., 2011, 7, 2355-2373.

2 L. L. Hench, J. Mater. Sci.: Mater. Med., 2006, 17, 967-978.

3 E. Fiume, J. Barberi, E. Verné and F. Baino, J. Funct. Biomater., 2018, 9, 24.

4 V. Krishnan and T. Lakshmi, J. Adv. Pharm. Technol. Res., 2013, 4, 78-83.

5 J. T. Heikkilä, H. J. Aho, A. Yli-urpo, R. P. Happonen and A. J. Aho, Acta Orthop., 1995, 66, 463-467.

6 S. R. Cicco, D. Vona, R. Gristina, E. Sardella, R. Ragni, M. Lo Presti and G. M. Farinola, Bioengineering, 2016 3(4), 35.

7 P. J. Walsh, S. A. Clarke, M. Julius and P. B. Messersmith, Sci. Rep., 2017, 7(1), 1-13.

8 P. M. Brett, J. Harle, V. Salih, R. Mihoc, I. Olsen, F. H. Jones and M. Tonetti, Bone, 2004, 35, 124-133.

9 K. Rabel, R.-J. Kohal, T. Steinberg, P. Tomakidi, B. Rolauffs, E. Adolfsson, P. Palmero, T. Fürderer and B. Altmann, Sci. Rep., 2020, 10, 12810.

10 A. Amoda, L. Borkiewicz, A. Rivero-Müller and P. Alam, Mater. Today Commun., 2020, 24, DOI: 10.1016/j.mtcomm. 2020.100923 .
11 S. R. Cicco, D. Vona, E. De Giglio, S. Cometa, M. MattioliBelmonte, F. Palumbo, R. Ragni and G. M. Farinola, ChemPlusChem, 2015, 80, 1104-1112.

12 R. W. Drum and R. Gordon, Trends Biotechnol., 2003, 21, 325-328.

13 E. Paasche, The physiological ecology of phytoplankton, Blackwell Scientific, 1980, pp. 259-284.

14 F. E. Round, R. M. Crawford and D. G. Mann, Diatoms: Biology and Morphology of the Genera, 2007.

15 C. L. Schelske and E. F. Stoermer, Science, 1971, 173, 423-424.

16 J. C. Lewin, J. Gen. Physiol., 1954, 37, 589-599.

17 J. C. Lewin, J. Gen. Physiol., 1955, 39, 1-10.

18 Y. Del Amo and M. A. Brzezinski, J. Phycol., 1999, 35, 1162-1170.

19 V. Martin-Jézéquel, M. Hildebrand and M. A. Brzezinski, J. Phycol., 2000, 36, 821-840.

20 K. Thamatrakoln and A. B. Kustka, BioEssays, 2009, 31, 322-327.

21 E. Paasche, Mar. Biol., 1973, 19, 262-269.

22 M. Hildebrand, B. E. Volcani, W. Gassmann and J. I. Schroeder, Nature, 1997, 385, 688-689.

23 C. A. Durkin, J. A. Koester, S. J. Bender and E. V. Armbrust, J. Phycol., 2016, 52, 716-731.

24 H. L. Conway, P. J. Harrison and C. O. Davis, Mar. Biol., 1976, 35, 187-199.

25 P. J. Harrison, H. L. Conway, R. W. Holmes and C. O. Davis, Mar. Biol., 1977, 43, 19-31.

26 P. Bhattacharyya and B. E. Volcani, Biochem. Biophys. Res. Commun., 1983, 114, 365-372.

27 M. L. Julius and E. C. Theriot, Applications for the Environmental and Earth Sciences, 2nd edn, 2010, pp. 8-22.

28 S. W. Chisholm, F. Azam and R. W. Eppley, Limnol. Oceanogr., 1978, 23, 518-529.

29 M. J. Knight, L. Senior, B. Nancolas, S. Ratcliffe and P. Curnow, Nat. Commun., 2016, 7, 11926.

30 R. W. Drum and H. S. Pankratz, J. Ultrastruct. Res., 1964, 10, 217-223.

31 N. Kroger and N. Poulsen, Handbook of Biomineralization, Wiley-VCH Verlag GmbH, Weinheim, Germany, 2008, Vol. 1, pp. 43-58.

32 S. B. Baines, M. Brzezinski, M. Hildebrand, M. Biogeochemistry, S. J. L. Lerch and R. P. Shrestha, Front. Mar. Sci., 2018, 1, 125.

33 S. Kumar, K. Rechav, I. Kaplan-Ashiri and A. Gal, Sci. Adv., 2020, 6(42), DOI: 10.1126/sciadv.aaz7554.

34 C. Gröger, M. Sumper and E. Brunner, J. Struct. Biol., 2008, 161, 55-63.

35 V. V. Annenkov, T. N. Basharina, E. N. Danilovtseva and M. A. Grachev, Protoplasma, 2013, 250, 1147-1155.

36 V. V. Annenkov, E. N. Danilovtseva, S. N. Zelinskiy, T. N. Basharina, T. A. Safonova, E. S. Korneva, Y. V. Likhoshway and M. A. Grachev, Anal. Biochem., 2010, 407, 44-51.

37 M. A. Grachev, Y. D. Bedoshvili, E. Y. Gerasimov, V. I. Zaikovskii, K. V. Gneusheva and Y. V. Likhoshway, Dokl. Biochem. Biophys., 2017, 472, 44-48.

38 E. G. Vrieling, Q. Sun, M. Tian, P. J. Kooyman, W. W. C. Gieskes, R. A. Van Santen and N. A. J. M. Sommerdijk, Proc. Natl. Acad. Sci. U. S. A., 2007, 104(25), 10441-10446. 
39 V. V. Annenkov, R. Gordon, S. N. Zelinskiy and E surname>Danilovtseva, J. Phycol., 2020, 56, 1729-1737.

40 R. E. Hecky, K. Mopper, P. Kilham and E. T. Degens, Mar. Biol., 1973, 19, 323-331.

41 K. Thamatrakoln, A. J. Alverson and M. Hildebrand, J. Phycol., 2006, 42, 822-834.

42 N. Kroger, Science, 1999, 286, 1129-1132.

43 N. Kroger, Science, 2002, 298, 584-586.

44 R. Wetherbee, Science, 2002, 298, 547.

45 S. Wenzl, R. Hett, P. Richthammer and M. Sumper, Angew. Chem., Int. Ed., 2008, 47, 1729-1732.

46 N. Kröger, R. Deutzmann, C. Bergsdorf and M. Sumper, Proc. Natl. Acad. Sci. U. S. A., 2000, 97, 14133-14138.

47 M. Sumper, E. Brunner and G. Lehmann, FEBS Lett., 2005, 579, 3765-3769.

48 M. C. Bridoux and A. E. Ingalls, Geochim. Cosmochim. Acta, 2010, 74, 4044-4057.

49 A. Jantschke, E. Koers, D. Mance, M. Weingarth, E. Brunner and M. Baldus, Angew. Chem., Int. Ed., 2015, 54, 15069-15073.

50 F. Kolbe, H. L. Ehren, S. Kohrs, D. Butscher, L. Reiß, M. Baldus and E. Brunner, Discover Mater., 2021, 1, 1-18.

51 J. D. Pickett-Heaps, Prog. Phycol. Res., 1990, 7, 1-168. pls. 1-101.

52 J. D. Pickett-Heaps, J. Phycol., 1998, 34, 995-1004.

53 A. M. L. Van De Meene and J. D. Pickett-Heaps, J. Phycol., 2002, 38, 351-363.

54 S. A. Crawford, M. J. Higgins, P. Mulvaney and R. Wetherbee, J. Phycol., 2001, 37, 543-554.

55 R. Wetherbee, S. Crawford and P. Mulvaney, Biomineralization, Wiley-VCH Verlag GmbH \& Co. KGaA, Weinheim, FRG, 2005, pp. 177-194.

56 W. E. G. Müller, Silicon Biomineralization, Springer Berlin Heidelberg, Berlin, Heidelberg, 2003, Vol. 33.

57 Molecular Mechanisms of Photosynthesis, ed. R. E. Blankenship, Blackwell Science Ltd, Oxford, UK, 2002.

58 B. J. Finkle and D. Appleman, Plant Physiol., 1953, 28, 664-673.

59 J. A. Raven, M. C. W. Evans and R. E. Korb, Photosynth. Res., 1999, 60, 111-150.

60 A. Gélabert, O. S. Pokrovsky, J. Schott, A. Boudou and A. FeurtetMazel, Geochim. Cosmochim. Acta, 2007, 71, 3698-3716.

61 A. Gélabert, O. S. Pokrovsky, C. Reguant, J. Schott and A. Boudou, J. Geochem. Explor., 2006, 88, 110-113.

62 I. Roth and J. P. Riley, J. Mar. Biol. Assoc. U. K., 1971, 51, 63-72.

63 H. J. Knauss and J. W. Porter, Plant Physiol., 1954, 29, 229-234.

64 J. Hayward, J. Mar. Biol. Assoc. U. K., 1969, 49, 439-446.

65 J. H. Martin and G. A. Knauer, Geochim. Cosmochim. Acta, 1973, 37, 1639-1653.

66 F. M. M. Morel, J. Phycol., 2007, 23, 137-150.

67 J. Lewin, Phycologia, 1966, 6, 1-12.

68 F. Azam, B. B. Hemmingsen and B. E. Volcani, Arch. Mikrobiol., 1973, 92, 11-20.

69 C. Jeffryes, T. Gutu, J. Jiao and G. L. Rorrer, ACS Nano, 2008, 2, 2103-2112.
70 M. Hildebrand, L. G. Frigeri and A. K. Davis, J. Phycol., 2007, 43, 730-740.

71 Y. Lang, F. del Monte, L. Collins, B. J. Rodriguez, K. Thompson, P. Dockery, D. P. Finn and A. Pandit, Nat. Commun., 2013, 4, 2683.

72 M. S. Chauton, L. M. B. Skolem, L. M. Olsen, P. E. Vullum, J. Walmsley and O. Vadstein, J. Appl. Phycol., 2015, 27, 777-786.

73 G. Leone, D. Vona, M. Lo Presti, L. Urbano, S. Cicco, R. Gristina, F. Palumbo, R. Ragni and G. M. Farinola, MRS Adv., 2017, 2, 1047-1058.

74 J. Li, J. Han, Q. Sun, Y. Wang, Y. Mu, K. Zhang, X. Dou, M. Kong, X. Chen and C. Feng, J. Mater. Chem. B, 2018, 6, 7834-7841.

75 Y. Lang, F. del Monte, B. J. Rodriguez, P. Dockery, D. P. Finn and A. Pandit, Sci. Rep., 2013, 3, 3205.

76 W. Brzozowska, M. Sprynskyy, I. Wojtczak, P. Dabek, A. Witkowski and B. Buszewski, Materials, 2020, 13, 2576.

77 F. Gentile, L. Tirinato, E. Battista, F. Causa, C. Liberale, E. M. di Fabrizio and P. Decuzzi, Biomaterials, 2010, 31, 7205-7212.

78 L. Li, K. Crosby and M. Sawicki, J. Biotechnol. Biomater., 2016, 2(6), DOI: 10.4172/2155-952X.1000150.

79 A. Zareidoost, M. Yousefpour, B. Ghaseme and A. Amanzadeh, J. Mater. Sci.: Mater. Med., 2012, 23, 1479-1488.

80 X. Liu, R. W. Y. Poon, S. C. H. Kwok, P. K. Chu and C. Ding, Surf. Coat. Technol., 2004, 186, 227-233.

81 S. F. Lamolle, M. Monjo, M. Rubert, H. J. Haugen, S. P. Lyngstadaas and J. E. Ellingsen, Biomaterials, 2009, 30, 736-742.

82 M. Yousefpour, A. Afshar, J. Chen and X. Zhang, Mater. Des., 2007, 28, 2154-2159.

83 N. B. Matsko, N. Žnidaršič, I. Letofsky-Papst, M. Dittrich, W. Grogger, J. Štrus and F. Hofer, J. Struct. Biol., 2011, 174, 180-186.

84 E. M. Carlisle, Science, 1970, 167, 279-280.

85 R. Jugdaohsingh, J. Nutr., Health Aging, 2007, 11, 99-110.

86 S. Heinemann, C. Heinemann, R. Bernhardt, A. Reinstorf, B. Nies, M. Meyer, H. Worch and T. Hanke, Acta Biomater., 2009, 5, 1979-1990.

87 K. Sahin, M. Onderci, N. Sahin, T. A. Balci, M. F. Gursu, V. Juturu and O. Kucuk, Poult. Sci., 2006, 85, 486-492.

88 T. D. H. Le, W. Bonani, G. Speranza, V. Sglavo, R. Ceccato, D. Maniglio, A. Motta and C. Migliaresi, Mater. Sci. Eng., C, 2016, 59, 471-479.

89 M. Wiens, X. Wang, H. C. Schröder, U. Kolb, U. Schlossmacher, H. Ushijima and W. E. G. Müller, Biomaterials, 2010, 31, 7716-7725.

90 J. R. Jones, Acta Biomater., 2013, 9, 4457-4486.

91 M. Terracciano, L. De Stefano and I. Rea, Pharmaceutics, 2018, 10, 242.

92 L. Köhler, S. Machill, A. Werner, C. Selzer, S. Kaskel and E. Brunner, Molecules, 2017, 22(12), DOI: 10.3390/molecules 22122232.

93 L. Rösch, P. John and R. Reitmeier, Ullmann's Encyclopedia of Industrial Chemistry, Wiley-VCH Verlag $\mathrm{GmbH} \&$ Co. KGaA, Weinheim, Germany, 2000, p. 1. 
94 C. Elschenbroich, Organometallics, 3rd edn, 2006.

95 V.-C. Niculescu, Front. Mater., 2020, 7, 1-14.

96 L. L. Hench and J. K. West, Chem. Rev., 1990, 90, 33-72.

97 C. J. Brinker and G. W. Scherer, in Sol-Gel Science, ed. C. J. Brinker and G. W. Scherer, Academic Press, San Diego, 1990, pp. xvi-18.

98 P. Singh, S. Srivastava and S. K. Singh, ACS Biomater. Sci. Eng., 2019, 5, 4882-4898.

99 L. Y. He, X. M. Zhang, B. Liu, Y. Tian and W. H. Ma, Braz. J. Med. Biol. Res., 2016, 49, 1-6.

100 S. Peng, X. S. Liu, S. Huang, Z. Li, H. Pan, W. Zhen, K. D. K. Luk, X. E. Guo and W. W. Lu, Bone, 2011, 49, 1290-1298.

101 W. B. Weglicki, B. F. Dickens, T. L. Wagner, J. J. Chmielinska and T. M. Phillips, Magnesium Res., 1996, 9, 3-11.
102 R. B. Kimble, S. Srivastava, F. P. Ross, A. Matayoshi and R. Pacifici, J. Biol. Chem., 1996, 271, 28890-28897.

103 M. H. Salimi, J. C. Heughebaert and G. H. Nancollas, Langmuir, 1985, 1, 119-122.

104 L. Cohen and R. Kitzes, Isr. J. Med. Sci., 1981, 17, 1123-1125.

105 J. Coulombe, H. Faure, B. Robin and M. Ruat, Biochem. Biophys. Res. Commun., 2004, 323, 1184-1190.

106 E. M. Brown, Osteoporosis Int., 2003, 14(Suppl 3), 25-34.

107 P. J. Kostenuik and V. Shalhoub, Curr. Pharm. Des., 2001, 7, 613-635.

108 S. Peng, X. S. Liu, G. Zhou, Z. Li, K. D. K. Luk, X. E. Guo and W. W. Lu, J. Bone Miner. Res., 2011, 26, 1272-1282.

109 S. K. Tat, J. P. Pelletier, F. Mineau, J. Caron and J. MartelPelletier, Bone, 2011, 49(3), 559-567.

110 M. L. Julius, Paleontol. Soc. Pap., 2007, 13, 1-12. 